\title{
Timing of Delivery in Gestational Diabetes Mellitus: Need for Person-Centered, Shared Decision-Making
}

Bharti Kalra $\cdot$ Yashdeep Gupta $\cdot$ Sanjay Kalra

Received: December 3, 2015 / Published online: March 9, 2016

(C) The Author(s) 2016. This article is published with open access at Springerlink.com

\begin{abstract}
Gestational diabetes mellitus (GDM) is a medical as well as obstetric challenge, which needs person-centered management. The timing of delivery of women with GDM is discussed by various obstetric professional bodies. We highlight pertinent medical, obstetric, and psychosocial factors which may influence the timing of delivery in women with GDM. This commentary proposes a person-centered approach to decide the delivery timing in GDM and supports shared decision-making based upon the individual's biopsychosocial characteristics and environmental factors.
\end{abstract}

Enhanced content To view enhance content for this article go to http://www.medengine.com/Redeem/ 8A44F060647AC1F6.

B. Kalra

Department of Obstetrics, Bharti Hospital, Karnal, India

Y. Gupta

Department of Endocrinology, AIIMS, New Delhi, India

\section{S. Kalra $(\bowtie)$}

Department of Endocrinology, Bharti Hospital, Karnal, India

e-mail: brideknl@gmail.com
Keywords: Antenatal corticosteroid therapy; Cephalopelvic disproportion; Diabetes; Fetomaternal distress; Labor; Macrosomia

\section{INTRODUCTION}

The prevalence of gestational diabetes mellitus (GDM) is rapidly increasing across the world and it is a common endocrine complication in obstetric practice today [1-3]. GDM, as a syndrome, is marked by controversy related to virtually every facet, ranging from its nomenclature, screening tools, and diagnosis to management strategies $[4,5]$. Most debate on GDM management centers on medical issues, such as appropriateness of oral hypoglycemic agents. In this communication, we discuss the timing of delivery in GDM and emphasize the need for person-centered, shared decision-making in this regard.

\section{Compliance with Ethics Guidelines}

This article does not contain any new studies with human or animal subjects performed by any of the authors. 


\section{CURRENT RECOMMENDATIONS}

Expert recommendations suggest that women with uncomplicated GDM take their pregnancies to term, and deliver at 38 weeks gestation [6]. Such a decision is not as simple as it seems. These recommendations differ from earlier findings, which suggested earlier induction of labor [7], but are consonant with secular trends in obstetrics, which support longer periods of gestation. Guidelines also state that GDM per se is not a factor in determining mode of delivery $[6,8]$.

The American College of Obstetricians and Gynecologists and the Society for Maternal Fetal Medicine have proposed new recommendations for terminology of gestational age and delivery timing [6]. For women with well-controlled diabetes, whether pregestational or gestational, a late preterm or early term birth, i.e., before 39 completed weeks of gestation, is not indicated. In a setting of poorly controlled diabetes, an individualized decision aiming for late preterm or early term delivery (before 38 weeks +6 days gestation) is recommended. An early term or term delivery (38-39 weeks +6 days gestation) is suggested if vascular complications are present in women with pregestational diabetes. In practice, however, these gestational ages may be difficult to attain. It must also be remembered that these recommendations assume 24/7 availability, accessibility, and affordability of optimal maternal and fetal monitoring, including seven-point glycemic profiles and regular cardiotocography for all women with GDM. They also take certain attributes of physical environment, such as ease of travel and communication, for granted.

\section{PERSON-SPECIFIC ATTRIBUTES OF GDM}

GDM, however, is not a homogenous entity. Each woman with GDM faces unique challenges with respect to her ethnicity, biomedical condition, psychological makeup, and social support system [9]. These factors influence postpartum health as well [10]. All these factors may potentially impact obstetric decision-making. While robust guidelines are available to help such decision-making $[6,11]$, the quality of many guidelines needs to be improved. There is discrepancy regarding induction of labor [12]. There is, therefore, a need to revisit the factors which may determine the timing of delivery. These obstetric, biomedical, and psychosocial factors influence the course of pregnancy complicated by diabetes and inform decision-making related to mode and timing of delivery (Table 1 ). We highlight some of these factors in the following paragraphs.

\section{BIOMEDICAL FACTORS}

The obstetrician considers many obstetric and medical factors while planning the delivery in a woman with GDM. These are listed in Table 1. Some of these factors play a role in decision-making for all deliveries, irrespective of the presence of diabetes. Certain issues, however, merit greater attention in women with GDM.

In general, waiting at least until 38 completed weeks' gestation improves fetal outcome, especially in diabetic patients [13]. However, if an indication for early delivery exists, GDM should not be considered as a contraindication to proceed with interventions 
Table 1 Factors influencing timing of delivery in GDM

\begin{tabular}{|c|c|c|}
\hline Factors & $\begin{array}{l}\text { Favoring early term delivery } \\
\text { (<39 weeks gestation) }\end{array}$ & $\begin{array}{l}\text { Favoring term delivery } \\
\text { ( } \geq 39 \text { weeks gestation) }\end{array}$ \\
\hline $\begin{array}{l}\text { Past obstetric } \\
\text { factors }\end{array}$ & $\begin{array}{l}\text { H/o previous pregnancy loss } \\
\text { H/o previous IUD at term } \\
\text { H/o macrosomia } \\
\text { H/o previous caesarian sections }\end{array}$ & No bad obstetric history \\
\hline $\begin{array}{l}\text { Current obstetric } \\
\text { factors }\end{array}$ & $\begin{array}{l}\text { H/o loss of fetal movement } \\
\text { Macrosomia (suspected fetal weight } \geq 4000 \mathrm{~g} \text { ) } \\
\text { IUGR } \\
\text { Compromised placental maturity }\end{array}$ & Optimal fetomaternal health \\
\hline Medical factors & $\begin{array}{l}\text { Uncontrolled diabetes } \\
\text { Retinal complications } \\
\text { Renal complications } \\
\text { Compromised cardiovascular health }\end{array}$ & Well-controlled, uncomplicated diabetes \\
\hline $\begin{array}{l}\text { Psychological } \\
\text { factors }\end{array}$ & Patient request for early LSCS & Patient reluctance for early delivery \\
\hline Social factors & $\begin{array}{l}\text { Availability of neonatology care } \\
\text { Ability to provide ACS coverage } \\
\text { Inability to come for frequent follow-up } \\
\text { Patient having to travel long distance for } \\
\text { obstetric/medical care }\end{array}$ & $\begin{array}{l}\text { Lack of specialist neonatology care } \\
\text { Inability to provide ACS coverage } \\
\text { Geographic proximity of health-care facility } \\
\text { Ability to travel comfortably and safely for } \\
\text { obstetric follow-up }\end{array}$ \\
\hline
\end{tabular}

GDM gestational diabetes mellitus, IUGR intrauterine growth retardation, LSCS lower segment caesarian section, ACS antenatal corticosteroid therapy, $H / o$ history of

for early delivery. Also, if a spontaneous preterm delivery seems imminent, it should not be postponed [14]. At times, in fact, an early, planned operative delivery may be appropriate for women with ketosis or ketoacidosis [15], difficult-to-control diabetes, with frequent episodes of hypoglycemia or hyperglycemia, excessively high insulin requirements, or any other clinical situation which may put the fetus at risk [16]. This may also be true for women with compromised cardiovascular, renal, or retinal function.
Macrosomia is a common accompaniment of GDM, especially in women with uncontrolled glycemia [16]. The risk of cephalopelvic disproportion (CPD) and shoulder dystocia increases as fetal weight gain occurs with advancing gestational age. The chances of a normal vaginal delivery, therefore, may recede as gestation progresses in women with refractory GDM, or in women on excessively high doses of insulin. In non-diabetic women, induction of labor for suspected macrosomia, at 39 weeks gestation, has been found to be 
cost-effective [17] in reducing maternal complications.

\section{PSYCHOSOCIAL FACTORS}

This issue is important in cultures where a premium is placed upon a woman's ability to have normal childbirth, where the parturient is unable to afford the physical rest required after surgical delivery, or if the financial burden associated with an operative delivery has to be paid by the patient. These realities imply that an earlier, planned delivery, at 36-37 weeks gestation, may be indicated in select women with GDM, who wish to try and maximize the chances of a normal vaginal delivery. Induction of labor at less than 40 weeks gestation in women with mild GDM does not increase the risk of LSCS [18]. In fact, the risk of LSCS rises threefold in women who are induced at 41 weeks, as compared to those who are induced at 39 weeks [18].

\section{ENVIRONMENTAL FACTORS}

Apart from the psychosocial factors discussed above, other external determinants play a role in deciding the timing of delivery. Availability of medical support (needed to manage glycemia after antenatal corticosteroid (ACS) therapy), of facilities and expertise for assisted vaginal delivery (ventouse, forceps), of facilities for operative delivery (including anesthesiology), and of neonatal care influence the choice of timing and mode of delivery. Lack of neonatology or medicine expertise supports a decision to continue women with GDM to term, rather than risk a clinical situation where the mother, with iatrogenic hyperglycemia secondary to ACS, or the preterm neonate, delivered by induced labor, cannot be managed.
The distance that a woman with GDM has to travel to access health care, the ease with which the journey is negotiated, and the feasibility of regular frequent follow-up also influence the mode and timing of delivery. Early induction of labor may be appropriate for women who find it difficult or expensive to travel repeatedly to the health-care center, for whom travel is uncomfortable or fraught with physical risk, or who are unable to adhere to the recommended frequency of follow-up. While we understand that these scenarios may seem implausible to many readers, they are the reality for people living with diabetes in many parts of the world $[19,20]$.

\section{SHARED DECISION-MAKING}

Decision regarding the mode and timing of delivery is a major challenge in routine obstetric care. This is especially true for women with GDM. The nature of the condition is such that it is challenging to conduct randomized controlled trials to assess the impact of the mode and timing of delivery on fetomaternal health. One must rely upon observational data, experience, and "good clinical sense" to decide the optimal method of delivery. The biopsychosocial model [21], coupled with shared decision-making, provides a useful framework to help solve this clinical dilemma.

The patient, and her family, including husband and mother-in-law [20], should be counseled about the potential benefits and harms of early (prior to 39 weeks gestation) and delayed delivery. Her views and preferences must be ascertained and appropriate decisions taken. Input from other medical professionals, who are an integral part of the GDM care team, should also be considered. Anticipated baby weight and placental maturity, determined by 
the radiologist; Bishop's score, calculated by the obstetrician or midwife; maternal and family attitudes towards caesarian section, ascertained by the diabetes educator or psychologist; and suitability or risk stratification for anesthesia must all be taken into account while planning the time of delivery (Table 1).

It must be remembered, though, that in all decision-making, maternal and fetal safety come first. Shared decision-making can be considered in situations characterized by clinical equipoise, where more than one therapeutic option is available [22]. For example, a woman with GDM, with a good sized baby ( $>4000 \mathrm{~g}$ weight) [23]) on abdominal or ultrasonographic examination, presenting at 37-38 weeks with a history of recent weight gain, and favorable cervical findings on per vaginum examination may be given the option of induction of labor. On the other hand, a scenario with maternal distress or fetal distress leaves no room for prevarication: informed consent for labor induction is absolutely necessary to ensure maternal and fetal well-being.

\section{CONCLUSION}

The timing of delivery in GDM is an important decision, which should be taken keeping in mind the biomedical, psychological, social, and environmental factors operating in the particular person. Such a decision is best arrived at through a process of active, informed discussion with the patient and her family.

\section{ACKNOWLEDGMENTS}

No funding or sponsorship was received for this study or publication of this article. All named authors meet the International Committee of Medical Journal Editors (ICMJE) criteria for authorship for this manuscript, take responsibility for the integrity of the work as a whole, and have given final approval for the version to be published.

Disclosures. Bharti Kalra, Yashdeep Gupta, and Sanjay Kalra have nothing to disclose.

Compliance with Ethics Guidelines. This article does not contain any new studies with human or animal subjects performed by any of the authors.

Open Access. This article is distributed under the terms of the Creative Commons AttributionNonCommercial 4.0 International License (http://creativecommons.org/licenses/by-nc/4. $0 /$ ), which permits any noncommercial use, distribution, and reproduction in any medium, provided you give appropriate credit to the original author(s) and the source, provide a link to the Creative Commons license, and indicate if changes were made.

\section{REFERENCES}

1. Ignell C, Claesson R, Anderberg E, Berntorp K. Trends in the prevalence of gestational diabetes mellitus in southern Sweden, 2003-2012. Acta Obstet Gynecol Scand. 2014;93(4):420-4.

2. Bardenheier BH, Imperatore G, Gilboa SM, Geiss LS, Saydah SH, Devlin HM, et al. Trends in gestational diabetes among hospital deliveries in 19 US States, 2000-2010. Am J Prev Med. 2015;49(1):12-9.

3. Guariguata L, Linnenkamp U, Beagley J, Whiting DR, Cho NH. Global estimates of the prevalence of hyperglycaemia in pregnancy. Diabetes Res Clin Pract. 2014;103(2):176-85.

4. Barbour LA. Unresolved controversies in gestational diabetes: implications on maternal and infant health. Curr Opin Endocrinol Diabetes Obes. 2014;21(4):264-70. 
5. Kalra B, Gupta Y, Baruah MP. Renaming gestational diabetes mellitus: a psychosocial argument. Indian J Endocrinol Metabol. 2013;17(9):593.

6. American College of Obstetricians and Gynecologists. ACOG committee opinion no. 560: medically indicated late-preterm and early-term deliveries. Obstet Gynecol. 2013;121:908-10.

7. Hod M, Bar J, Peled Y, Fried S, Katz I, Itzhak M, et al. Antepartum management protocol. Timing and mode of delivery in gestational diabetes. Diabetes Care. 1998;21:B113-7.

8. American College of Obstetricians and Gynecologists. ACOG committee opinion no. 579: definition of term pregnancy. Obstet Gynecol. 2013;122:1139-40.

9. Kalra B, Sridhar GR, Madhu K, Balhara YP, Sahay RK, Kalra S. Psychosocial management of diabetes in pregnancy. Indian $\mathrm{J}$ Endocrinol Metabol. 2013;17(5):815.

10. Walmer R, Huynh J, Wenger J, Ankers E, Mantha $\mathrm{AB}$, Ecker $\mathrm{J}$, et al. Mental health disorders subsequent to gestational diabetes mellitus differ by race/ethnicity. Depress Anxiety. 2015;32(10):774-82.

11. Blumer I, Hadar E, Hadden DR, Jovanovič L, Mestman JH, Murad MH, et al. Diabetes and pregnancy: an Endocrine Society clinical practice guideline. J Clin Endocrinol Metab. 2013;98(11):4227-49.

12. Greuter MJ, van Emmerik NM, Wouters MG, van Tulder MW. Quality of guidelines on the management of diabetes in pregnancy: a systematic review. BMC Pregnancy Childbirth. 2012;12(1):1.

13. Gawlik S, Müller M, Kuon RJ, Szabo AZ, Keller D, Sohn C. Timing of elective repeat caesarean does matter: importance of avoiding early-term delivery especially in diabetic patients. J Obstet Gynaecol. 2015;35(5):455-60.
14. Aviram A, Guy L, Ashwal E, Hiersch L, Yogev Y, Hadar E. Pregnancy outcome in pregnancies complicated with gestational diabetes mellitus and late preterm birth. Diabetes Res Clin Pract. 2016. doi:10.1016/j.diabres.2015.12.018

15. Frise CJ, Ashcroft A, Jones BA, Mackillop L. Pregnancy and ketoacidosis: is pancreatitis a missing link? Obstet Med Med Pregnancy. 2015. doi:10.1177/1753495X15612330.

16. Ballas J, Moore TR, Ramos GA. Management of diabetes in pregnancy. Curr Diab Rep. 2012;12(1):33-42.

17. Lee VR, Niu B, Kaimal A, Caughey AB. Induction of labor for suspected macrosomia: a cost-effectiveness analysis. Obstet Gynecol. 2015;1(125):103S.

18. Sutton AL, Mele L, Landon MB, Ramin SM, Varner MW, Thorp JM, et al. Delivery timing and cesarean delivery risk in women with mild gestational diabetes mellitus. Am J Obstet Gynecol. 2014;211(3):244-5.

19. Kalra S, Sridhar GR, Balhara YP, Sahay RK, Bantwal G, Baruah MP, et al. National recommendations: psychosocial management of diabetes in India. Indian J Endocrinol Metab. 2013;17(3):376.

20. Bajaj S, Jawad F, Islam N, Mahtab H, Bhattarai J, Shrestha D, et al. South Asian women with diabetes: psychosocial challenges and management: consensus statement. Indian J Endocrinol Metab. 2013;17(4):548.

21. Engel GL. The need for a new medical model: a challenge for biomedicine. Science. 1977;196:129-36.

22. Baruah MP, Kalra B, Kalra S. Patient centred approach in endocrinology: from introspection to action. Indian J Endocr Metab. 2012;16:679-81.

23. Peleg D, Warsof S, Wolf MF, Perlitz Y, Shachar IB. Counseling for fetal macrosomia: an estimated fetal weight of 4,000 $\mathrm{g}$ is excessively low. Am J Perinatol. 2015;32(1):71-4. 